\title{
Study of Human Serum Albumin Adsorption and Conformational Change on DLC and Silicon Doped DLC Using XPS and FTIR Spectroscopy
}

\author{
Mukhtar H. Ahmed ${ }^{1 *}$, John A. Byrne ${ }^{1}$, James McLaughlin ${ }^{1}$, Waqar Ahmed ${ }^{2}$ \\ ${ }^{1}$ Nanotechnology Integrated Bio-Engineering Centre, University of Ulster, Belfast, UK; ${ }^{2}$ Institute of Nanotechnology and Bioengi- \\ neering, University of Central Lancashire, Preston, UK. \\ Email: ${ }^{*}$ ahmed-m@email.ulster.ac.uk
}

Received January $20^{\text {th }}, 2013$; revised March $10^{\text {th }}, 2013$; accepted April $14^{\text {th }}, 2013$

Copyright (C) 2013 Mukhtar H. Ahmed et al. This is an open access article distributed under the Creative Commons Attribution License, which permits unrestricted use, distribution, and reproduction in any medium, provided the original work is properly cited.

\begin{abstract}
Diamond-like carbon (DLC) coatings are extremely useful for creating biocompatible surfaces on medical implants. DLC and silicon doped DLC synthesised on silicon wafer substrate by using plasma enhanced chemical vapour deposition (PECVD). The effects of surface morphology on the interaction of HSA with doped and undoped DLC films have been investigated. The chemical composition of the surface before and after adsorption was analysed using X-ray photoelectron spectroscopy (XPS) and Fourier transform infrared (FTIR). Results showed that silicon incorporation DLC tends to increase of $\mathrm{sp}^{3} / \mathrm{sp}^{2}$ hybridization ratio by decreasing $\mathrm{sp}^{2}$ hybridized carbon bonding configurations. Following exposure to solutions containing $(0.250 \mu \mathrm{g} / \mathrm{ml}) \mathrm{HSA}$, the results indicated that significant changes in the $\mathrm{C}, \mathrm{N}$ and $\mathrm{O}$ levels on the surfaces with reducing of the Si2p band at $100 \mathrm{eV}$. From FTIR spectrum, the peaks occur the following functional groups were assigned as amide I and II groups at $1650 \mathrm{~cm}^{-1}$ and $1580 \mathrm{~cm}^{-1}$. Both XPS and FTIR spectroscopy confirm that HSA was bound onto the surfaces of the DLC and Si-DLC films via interaction of ionized carboxyl groups and the amino group did not play a significant role in the adsorption of protein. These results from peak intensity show that an adsorbed layer of HSA is higher at high level (19\%) silicon doping. Therefore doping of DLC may provide an approach to controlling the protein adsorption.
\end{abstract}

Keywords: Diamond Like Carbon; Si-DLC; HAS; Adsorption; XPS; FTIR

\section{Introduction}

Analysing the interaction of proteins with the surfaces of materials intended for biomedical applications is fundamental for understanding cellular events and the overall host response. Furthermore, the importance of a variety of molecules in the biomedical field is known for several applications, including drug delivery, biomaterials, extracorporeal therapy and solid-phase diagnostics [1]

Both the nature of the biomaterial and the protein has effects on the adsorption process. The most significant surface properties of biomaterials, including the elemental composition, functional groups and surface energy are very important. All of these parameters play a role in enhancing or decreasing the adsorption of proteins or biological compounds during the implant.

Diamond like carbon (DLC) is an ideal candidate for

${ }^{*}$ Corresponding author. use as biocompatible coatings on biomedical implants [2] such as coronary artery stents [3], artificial hearts, mechanical heart valves [4], hip and knee replacements [5] and rotary blood pumps [6]. Furthermore DLC possess a unique combination of desirable properties including chemical inertness, high density, heamocompatibility and poor coefficient of friction [7].

Comparative studies improved doped DLC possesses better surface biocompatibility than the undoped counterpart [8]. Thus, to enhance the biocompatibility of DLC, the incorporation of third element dopants like nitrogen [9], fluorine [10], silicon [11] and titanium [12], may be necessary.

Silicon modification has been greatly applied in medical devices and many investigations reported the chemical stability of silicon doped DLC [13]. Silicon incorporation into DLC has been proven to overcome some of the stated drawbacks, including low intrinsic compres- 
sive stress, good adhesion, and mechanical resistance which are beneficial for biomedical applications $[14,15]$. Investigators have found an improvement in blood compatibility with silicon doped DLC film where a decrease of inflammatory reactions was observed as compared to undoped DLC [16].

To improve the understanding of the fundamentals of protein adsorption, many protein adsorption-modelling approaches have been successfully used.

In this contribution, we explore the coating of silicon wafer substrate with DLC and silicon doped DLC thin films using plasma enhanced chemical vapour deposition (PECVD). The adsorption of human serum albumin (HSA) on these films is investigated, since its adsorption onto surgical instruments and medical devices is likely to dominate in vivo due to its abundance in human serum. The physico-chemical properties of adsorption process were evaluated by different techniques using X-ray photoelectron spectroscopy (XPS) and Fourier Transform Infrared (FTIR).

The aim of this study is to illustrate the conformational changes in HSA upon attachment to DLC and Si-DLC surfaces, in order to improve our understanding of the dynamic phenomena in protein adsorption.

\section{Experimental and Methods}

\subsection{Preparation and Modification of DLC}

Before deposition of the films, silicon wafers $1.5 \times 1.5$ $\mathrm{cm}^{2}$ were cleaned gently and sonicated for $5 \mathrm{~min}$ in acetone and isopropanol (1:1) followed by washing with distilled water and then dried using nitrogen gas. Doped and undoped diamond like carbon (DLC) were deposited on cleaned substrates by the radio frequency (RF) $13.56 \mathrm{MHz}$ Plasma Enhanced Chemical Vapour Deposition (PECVD) using a Diavac model 320PA (ACM Ltd.), with negative electrode self-bias voltages set at 400 Volt. The experimental equipment had been described previously in details [17]. The clean substrates are placed in the deposition chamber on top of a water-cooled electrode driven by an RF power supply.

When the chamber pressure reached $\sim 5 \times 10^{-6}$ Torr an Argon gas flow rate of $60 \mathrm{~mL} / \mathrm{min}$ was used for substrate surface cleaning. The films were prepared under the following conditions: $\mathrm{C}_{2} \mathrm{H}_{2}$ was used as source gas; Argon (Ar) and tetramethylsilane (TMS) $\left(\mathrm{Si}\left(\mathrm{CH}_{3}\right)_{4}[\% 99.8\right.$ SigmaAldrech]) were used as dopant source. The argonacetylene flow ratio $\left(\mathrm{Ar}\right.$ to $\left.\mathrm{C}_{2} \mathrm{H}_{2}\right)$ was fixed at (10:20) standard cubic centimetre $(\mathrm{sccm})$, and the deposition time was fixed for (5) minutes. To prepare the Si-DLC samples, the various doping concentrations of silicon were achieved using TMS, and a detail of the parameters is given in Table 1.
Table 1. The deposition conditions of DLC and Si-DLC samples using rf-PECVD system.

\begin{tabular}{lcccc}
\hline \multirow{2}{*}{ Parameters } & \multicolumn{4}{c}{ Samples } \\
\cline { 2 - 5 } & DLC & SI & SII & SIII \\
\hline $\begin{array}{l}\text { Pressure in Process } \\
\times 10^{-2} \text { (Torr) }\end{array}$ & 0.75 & 0.89 & 1.32 & 1.76 \\
$\begin{array}{l}\text { TMS (sccm) } \\
\text { Film thickness (nm) }\end{array}$ & 0 & 2 & 5 & 10 \\
\hline
\end{tabular}

Bias voltage: 400 volt, deposition time: 5 minute, (TMS): Tetramethylsilane, $(\mathrm{sccm})$ : standard centimetre cube per minute, $\mathrm{Ar}$ : $\mathrm{C}_{2} \mathrm{H}_{2}$ ratio: 10:20 $(\mathrm{sccm})$, $(\mathrm{nm})$ : nanometre, Initial chamber pressure: $\sim 5 \times 10^{-6}$ Torr, $( \pm)$ is $\mathrm{SD}$ for $\mathrm{n}=$ 7 samples.

\subsection{Adsorption of Human Serum Albumin (HSA) on DLC and Si-DLC Samples}

Human serum albumin (HSA) [from Sigma Aldrich] was prepared in phosphate buffer saline (PBS) [from SigmaAldrich] to give solution having concentration of 250 $\mu \mathrm{g} / \mathrm{ml}$ and the $\mathrm{pH}$ was adjusted at 7.4.

The prepared samples were immersed in the $10 \mathrm{ml}$ of HSA solution $(250 \mu \mathrm{g} / \mathrm{ml})$ separately in sealed jars and incubated for 60 minute at $37^{\circ} \mathrm{C} \pm 1^{\circ} \mathrm{C}$ using thermostatic shaker bath. After the period time, the samples were then washed twice with distilled water and dried using nitrogen gas.

\subsection{Surface Characterisation}

XPS measurements were obtained using a KRATOS XSAM 800 equipped with an energy analyser. The X-ray source employed was $\mathrm{Al} \mathrm{K} \alpha \mathrm{X}$-ray source $(h v 1486 \mathrm{eV})$ generated from aluminium anode operating at the emission voltage at $15 \mathrm{keV}$ and $5 \mathrm{~mA}$. The base pressure within the spectrometer during examination was $\sim 8 \times 10^{-10}$ bar. All spectra were referenced by setting the hydrocarbon $\mathrm{C} 1 \mathrm{~s}$ peak to $285.0 \mathrm{eV}$ to compensate for residual charging effects.

The film thickness of the prepared samples was obtained using a stylus profilometer (Dektak 8 Advanced Stylus Profiler Veeco Instruments Inc., USA). Automatic levelling was selected and system based software performed average step height calculations.

The chemical bonding configurations were characterized by Fourier transform infrared spectroscopy FTIR at room temperature using BIORAD Excalibur (FTS 3000 MX series) instrument, to investigate the various chemical vibrational modes the spectrum was recorded in the region of $4000-400 \mathrm{~cm}^{-1}$ and 60 scans were accumulated at a resolution of $4 \mathrm{~cm}^{-1}$. In all of the FTIR experiments the background spectrum was collected before the actual sample analysis using the relevant unattached coated samples with Human serum albumin (HSA) and 
this signature was subsequently removed from the sample scan. The subsequent analysis of the attached HSA on the DLC and Si-DLC samples was performed.

\section{Results and Discussion}

\subsection{Surface Characterisation of Prepared Samples}

The film thicknesses of DLC and Si-DLC samples have been obtained and the values were arranged from $\sim(157$ 218) $\mathrm{nm}$, the growth rate of film deposition was around $(38 \pm 6) \mathrm{nm} \cdot \mathrm{min}^{-1}$ (Table 1).

Figure 1 shows the survey scan of XPS spectra of doped and undoped DLC. The main peaks were observed at $\sim 285.1 \mathrm{eV}$, and $\sim 531.4 \mathrm{eV}$, corresponding to $\mathrm{C} 1 \mathrm{~s}$ and $\mathrm{O} 1 \mathrm{~s}$, bands, respectively. The addition peak was revealed at $100.7 \mathrm{eV}$ [in case of silicon doped DLC] which attributed to $\mathrm{Si} 2 \mathrm{p}$.

$\mathrm{C} 1 \mathrm{~s}$ spectrum of DLC has been deconvoluted in to three different peaks. The first band located at $284.7 \mathrm{eV}$, is related to the $\mathrm{sp}^{2}$ hybridized carbon $(\mathrm{C}=\mathrm{C})$. A band at $285.3 \mathrm{eV}$, is corresponded to $\mathrm{a} \mathrm{sp}^{3}$ carbon (C-C), and last peak was obtained at $287.4 \mathrm{eV}$, can be related to the (CO) bonds (Figure 2). The carbon atom percentage in the DLC is determined as $86.70 \%$ (Table 2).

It has been observed that the presence of silicon in the film affected the binding energy by causing a slight lowering in the energy accompanied by a broadening of the $\mathrm{C} 1 \mathrm{~s}$ peaks with $\mathrm{FWHM}$ of $2.5 \mathrm{eV}$, which increased with increasing silicon concentration in the films. The $\mathrm{C} 1 \mathrm{~s}$ spectrum of Si-DLC yielded four deconvoluted peaks; at $283.9 \mathrm{eV}$ [Si-C], $284.7 \mathrm{eV}$ [C=C], $285.3 \mathrm{eV}$ [C-C], 287.3 $\mathrm{eV}$ [CO] [18]. On the other hand, the intensity of both $\mathrm{Si}-\mathrm{C}$ and $\mathrm{C}-\mathrm{C}$ increased with increasing the silicon concentration in the films, the results agree with those obtained by Zhao et al. [19].

The properties of the DLC thin films depend mainly on its structure resulting from combination of $\mathrm{sp}^{3}$ bonding (Diamond form) and $\mathrm{sp}^{2}$ (graphite form). The $\mathrm{sp}^{3}$ to $\mathrm{sp}^{2}$ ratio is dependent on the deposition process and its parameters. The incorporation of silicon into DLC leads to the decrease of $\mathrm{C}=\mathrm{C}\left(\mathrm{Sp}^{2}\right)$ bonded with increase of $\mathrm{C}$-Si contribution, while the amount of the $\mathrm{C}-\mathrm{C}$ bonding $\left(\mathrm{sp}^{3}\right)$ remained relatively unaltered. The results show that silicon atoms preferentially substitute the $\mathrm{sp}^{2}$ hybridized carbon atoms during film formation. Then one may conclude that silicon content can increase the $\mathrm{sp}^{3} / \mathrm{sp}^{2}$ ratio in the film (Figure 3). This tends to improve the compatibility of the implant with blood components [20].

The XPS O1s spectra of DLC and Si-DLC samples were located at $\sim 531 \mathrm{eV}$ (Figure 4). Deconvolution of the $\mathrm{O} 1 \mathrm{~s}$ band gave two sub peaks around $531 \mathrm{eV}$ and 532 $\mathrm{eV}$, which are attributed to $(\mathrm{C}=\mathrm{O})$ and $(\mathrm{C}-\mathrm{O})$ bond in the film structure, respectively.

The results of the XPS analysis of the O1s region of the Si-DLC samples showed that the oxygen concentration in the films increases with increasing silicon flow rate, (Table 2). The obtained results are in good agreement with those provided previously determined values [11].

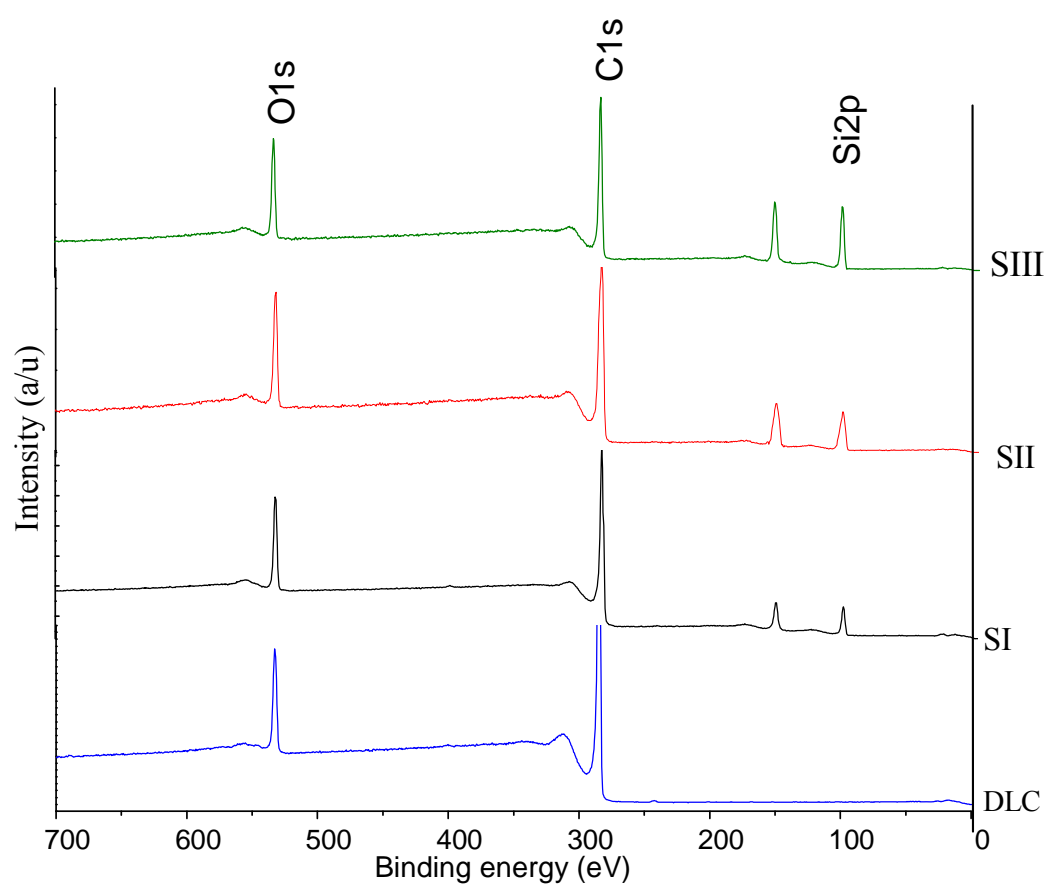

Figure 1. XPS survey scans for DLC and Si-DLC (SI, SIII and SIII) samples. 

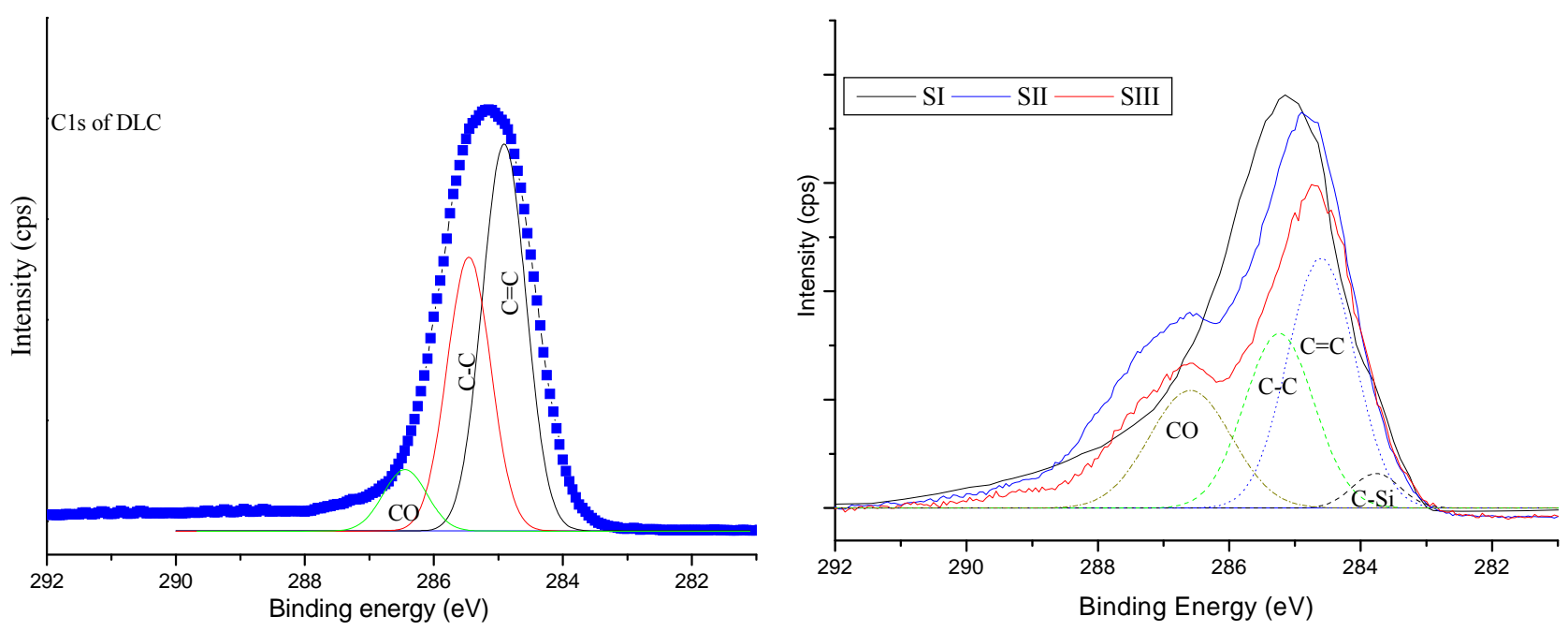

Figure 2. XPS C1s spectra deconvolution of DLC and Si-DLC samples.

Table 2. XPS survey data (atomic percentage) for the elements on to surface of samples before and after adsorption of HAS.

\begin{tabular}{|c|c|c|c|c|c|c|c|}
\hline \multirow{2}{*}{ Samples } & \multirow{2}{*}{ Peak designation } & \multicolumn{3}{|c|}{ Before adsorption of HSA } & \multicolumn{3}{|c|}{ After adsorption of HSA } \\
\hline & & Band $(\mathrm{eV})$ & At. $\%$ Conc. & FWHM (eV) & Band $(\mathrm{eV})$ & At. $\%$ Conc. & FWHM $(\mathrm{eV})$ \\
\hline \multirow{3}{*}{ DLC } & $\mathrm{C} 1 \mathrm{~s}$ & 285.1 & 86.7 & 1.5 & 284.9 & 62.5 & 2.0 \\
\hline & $\mathrm{O} 1 \mathrm{~s}$ & 531.4 & 13.3 & 2.4 & 532.1 & 32.6 & 2.2 \\
\hline & N1s & & & & 399.7 & 4.9 & 1.9 \\
\hline \multirow{4}{*}{ SI } & $\mathrm{C} 1 \mathrm{~s}$ & 284.9 & 81.9 & 1.8 & 285.0 & 62.7 & 2.1 \\
\hline & O $1 \mathrm{~s}$ & 532.1 & 13.7 & 2.3 & 532.0 & 31.9 & 2.1 \\
\hline & $\mathrm{Si} 2 \mathrm{p}$ & 100.7 & 4.4 & 1.6 & & & \\
\hline & N1s & & & & 399.5 & 5.4 & 2.2 \\
\hline \multirow{4}{*}{ SII } & $\mathrm{C} 1 \mathrm{~s}$ & 284.9 & 76.3 & 2.1 & 284.9 & 62.1 & 2.3 \\
\hline & $\mathrm{O} 1 \mathrm{~s}$ & 532.4 & 14.1 & 2.2 & 531.9 & 32.7 & 2.0 \\
\hline & $\mathrm{Si} 2 \mathrm{p}$ & 100.3 & 9.6 & 2.2 & & & \\
\hline & N1s & & & & 399.8 & 5.2 & 2.1 \\
\hline \multirow{4}{*}{ SIII } & $\mathrm{C} 1 \mathrm{~s}$ & 284.7 & 68.5 & 2.5 & 284.7 & 62.0 & 2.3 \\
\hline & O1s & 531.7 & 14.7 & 2.1 & 532.0 & 32.5 & 2.1 \\
\hline & $\mathrm{Si} 2 \mathrm{p}$ & 100.4 & 16.8 & 3.0 & & & \\
\hline & N1s & & & & 399.8 & 5.5 & 2.2 \\
\hline
\end{tabular}

On the other hand, the band related to silicon atom (Si2p) appeared at around $101 \mathrm{eV}$. The fitted band of $\mathrm{Si} 2 \mathrm{p}$ gives two sub-peaks centred at $100.6 \mathrm{eV}$ and 102.3 $\mathrm{eV}$ can be assigned to $\mathrm{Si}-\mathrm{C}$ and $\mathrm{Si}-\mathrm{O}$ bonds, respectively. The quantitative analysis of atomic percentage of silicon content DLC gives 4.4, 9.6 and 16.8 for SI, SII and SIII, respectively (Table 2).

Figure 5 shows the FTIR spectrum of doped and undoped DLC samples. Bands located at around $1450 \mathrm{~cm}^{-1}$ and $896 \mathrm{~cm}^{-1}$ are assigned to the stretching and bending of $\mathrm{C}-\mathrm{C} \mathrm{sp}^{3}$ hybridization respectively, and a medium band at $1210 \mathrm{~cm}^{-1}$ can also be assigned to the $\mathrm{sp}^{3}$ bond of carbon hybridisation [21]. This indicates the formation of tetrahedral carbon structures in the DLC films and the inclusion of hydrogen. The peak at $\sim 727 \mathrm{~cm}^{-1}$ belongs to the out of plane bending configuration of the graphite like carbon [22]. A weak peak at $1624 \mathrm{~cm}^{-1}$ is assigned to carbon double bond hybridization. In addition to the 


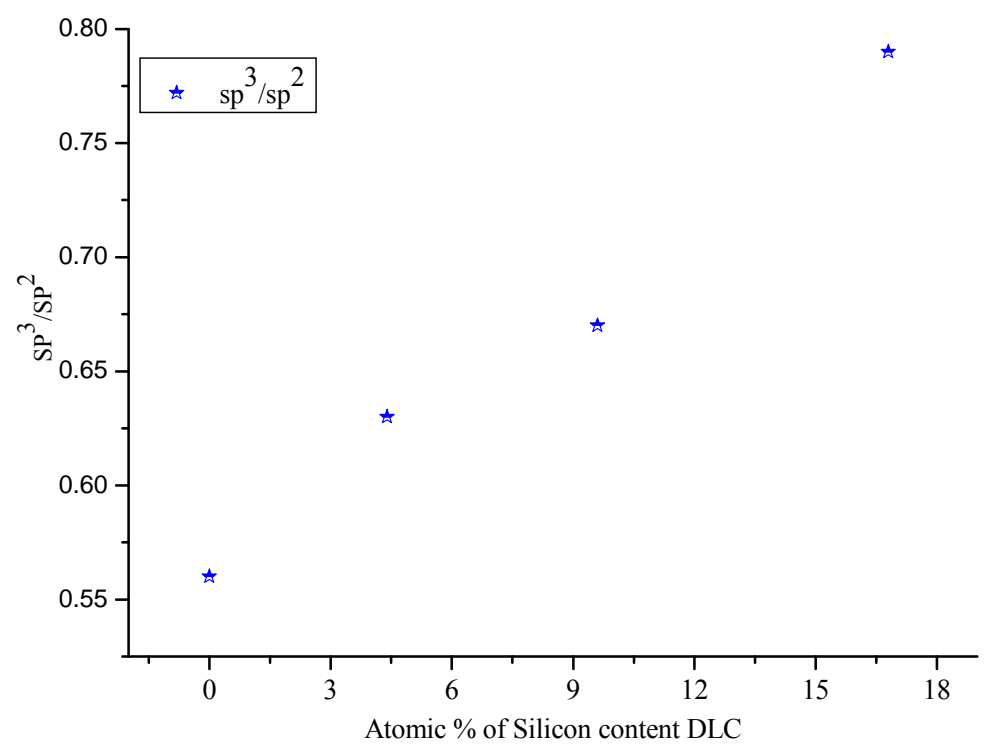

Figure 3. $\mathrm{sp}^{3} / \mathrm{sp}^{2}$ ratio in relation to atomic present of silicon content DLC.
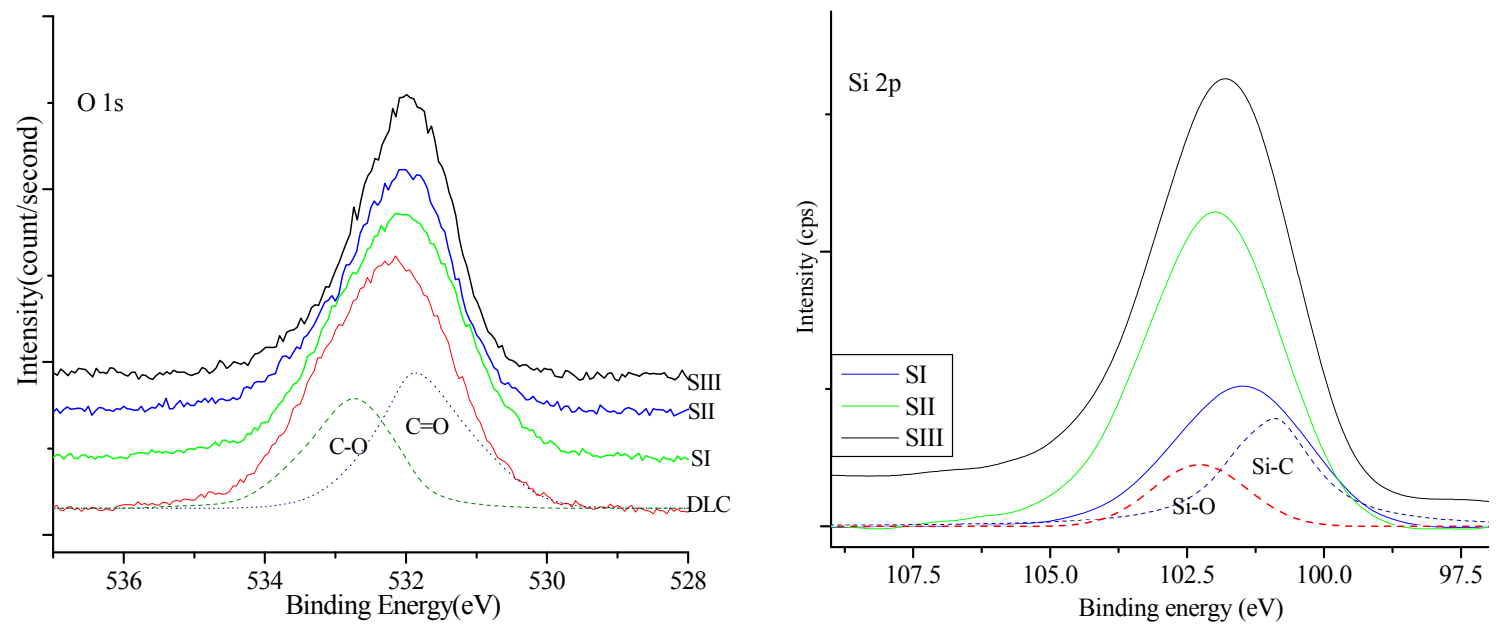

Figure 4. The XPS O1s and Si2p spectra of deposited samples.
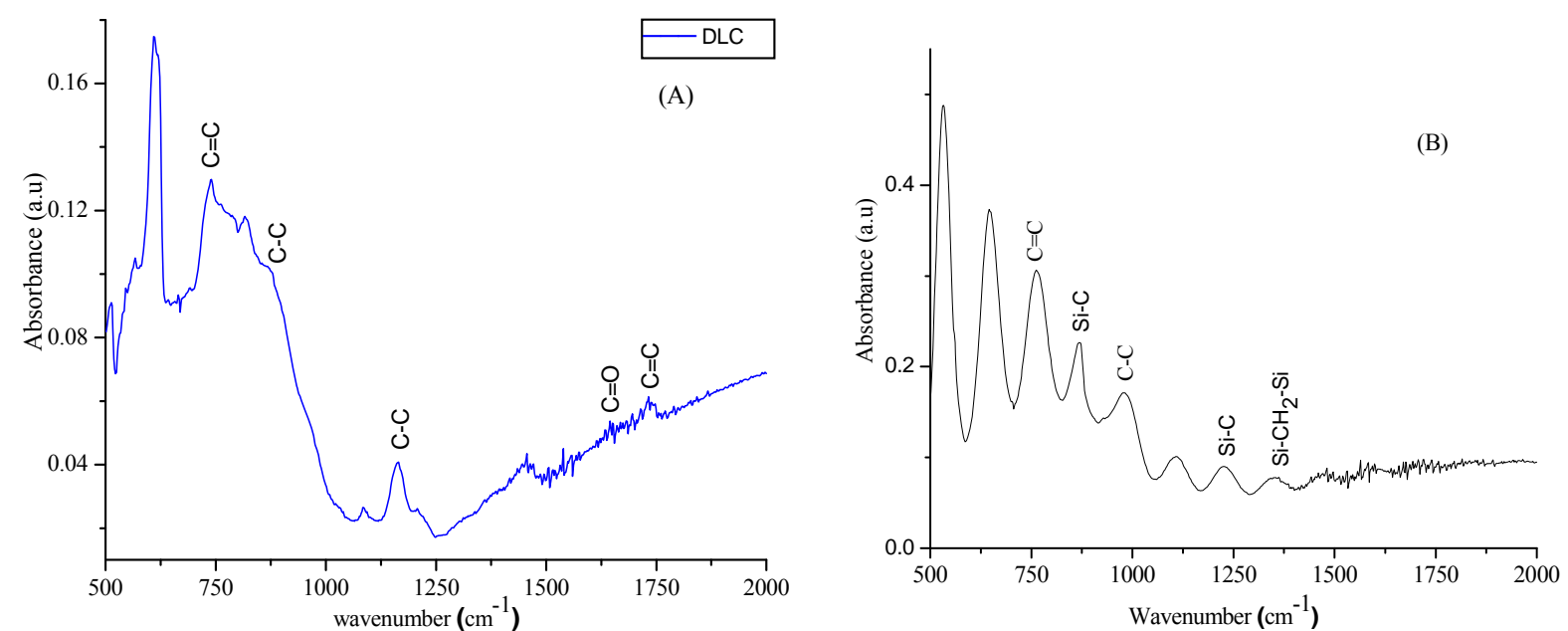

Figure 5. FTIR spectra of DLC (A) and Si-DLC (B). 
bands at $905 \mathrm{~cm}^{-1}$ and $1192 \mathrm{~cm}^{-1}$ which is return to the $\mathrm{C}-\mathrm{C}$ bonds, too. For Si-DLC samples, the bands have been detected at $880 \mathrm{~cm}^{-1}$, attributed to the $\mathrm{Si}-\mathrm{CH}$ bond [23]. in addition, the deformation vibration of $\mathrm{Si}-\mathrm{CH}_{3}$ bond was observed at $1263 \mathrm{~cm}^{-1}$ and a band appeared at around $1359 \mathrm{~cm}^{-1}$ suggested the presence of stretching vibration of $\mathrm{Si}-\mathrm{CH}_{2}-\mathrm{Si}$ bonds. The results are agree with those achieved by Finer et al. [24].

\subsection{Characteriztion of Surfaces after HSA Adsorption}

XPS was used to investigate the chemical surface composition during the HSA adsorption. The survey scan XPS spectrum of adsorbed HSA on the DLC and Si-DLC surfaces is presented in Figure 6. The results showed that a new signal at $400 \mathrm{eV}$ has observed is assigned to $\mathrm{N} 1 \mathrm{~s}$ band, and the $\mathrm{C} 1 \mathrm{~s}$ band intensity was significantly changed, along with a reduction in the $\mathrm{Si} 2 \mathrm{p}$ intensity (in case of Si-DLC). Furthermore, a weak band was detected at $164.1 \mathrm{eV}$ in the high-resolution analysis of the $\mathrm{S} 2 \mathrm{p}$ which can be attributed to sulphur atoms in cysteine amino acid [25]. These data indicate the presence of the protein on the surfaces [26].

High resolution analysis of the $\mathrm{C} 1 \mathrm{~s}$ peak after adsorption of protein was quite different from the samples prior to protein adsorption. The deconvolution of the $\mathrm{C} 1 \mathrm{~s}$ peak gave four different bands. The first component located at $\sim 285.2 \mathrm{eV}$ which assigned to saturated and unsaturated hydrocarbon groups. A peak at $286.7 \mathrm{eV}$ is related to $\mathrm{C}-\mathrm{NH}$ amine groups and the last peak detected at around $288.4 \mathrm{eV}$ is for the peptide bond $\mathrm{HN}-\mathrm{C}=\mathrm{O}$, (Figure 7).

After peak fitting of the N1s core-level spectrum, three deconvoluted peaks were observed at $399.7 \mathrm{eV}(73 \%)$, is attributed to $(\mathrm{C}-\mathrm{N})$, a peak showed at $401.7 \mathrm{eV}(19 \%)$ assigned to $\mathrm{N}-\mathrm{C}=\mathrm{O}$ and $\mathrm{N}-\mathrm{H}$ bonded [27], and the third band was appeared at $402.8 \mathrm{eV}(8 \%)$ is returned to positively charged amines $\left(\mathrm{NH}_{3}^{+}\right)$. The $\mathrm{NH}_{3}^{+}$component of N1s spectrum of Si-DLC samples shifts to a higher binding energy with a slight increase in band area, compared to the same band in undoped DLC. This might evidence that the HSA was adsorbed on to surfaces via carboxylic acid group [17].

The O1s band after protein adsorption is similar to that without protein, suggesting that the most of the signal is attributable to carbon oxides and surface $\mathrm{OH}$ groups (Figure 7). The amount of protein adsorbed onto a surface, can be related to the intensity of $\mathrm{C} 1 \mathrm{~s}$ peak. Hence, based on the $\mathrm{C} 1 \mathrm{~s}$ intensity, the relative amount of adsorbed HSA increases with increasing silicon doped DLC. Therefore, doping of DLC may allow control of protein adsorption to the surface.

\section{Fourier Transform Infrared (FTIR)}

FTIR spectroscopy can be used for identification of the functional group and showing different vibrational modes of various bonds which are present in the film. Figure 8 shows the FTIR spectrum of free and bounded HSA on to surface of coated DLC. The bands centred at around $1650 \mathrm{~cm}^{-1}$ and $1550 \mathrm{~cm}^{-1}$, which correspond to amide I and amide II, respectively. The location of both the Amide bond orientation are sensitive to the secondary structure of a protein, because both groups of $\mathrm{C}=\mathrm{O}$ and the $\mathrm{N}-\mathrm{H}$ bonds are involved in the hydrogen bonding that takes place between the different elements of secondary

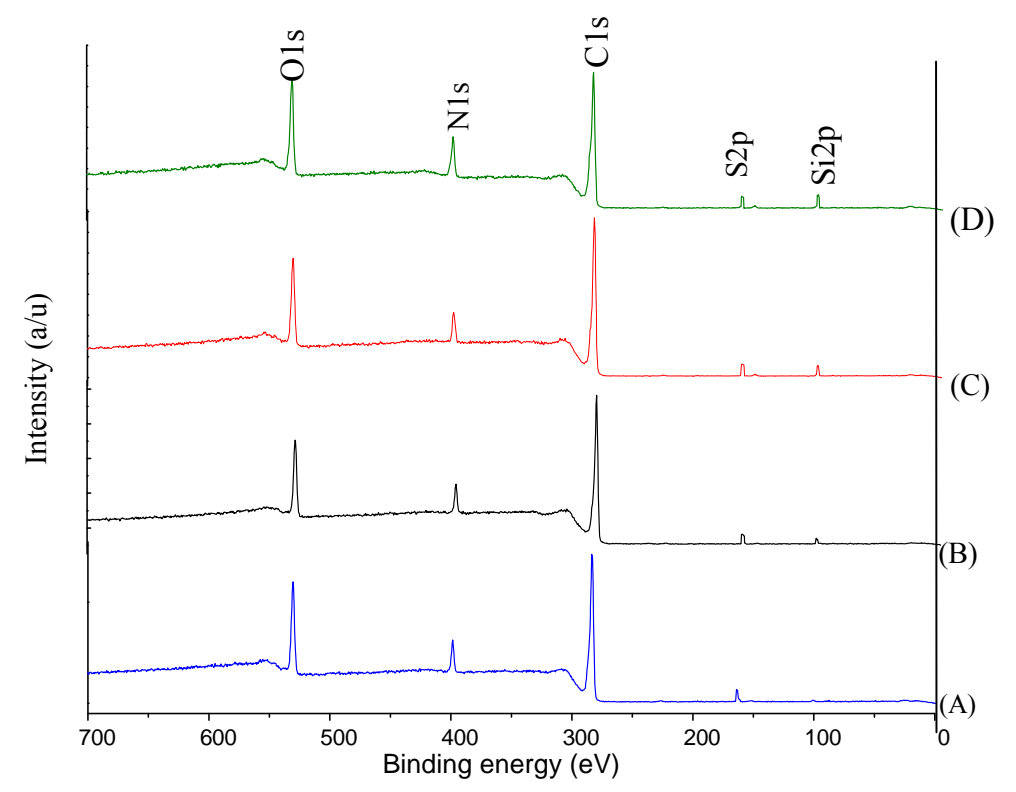

Figure 6. The XPS survey scan for DLC and Si-DLC surfaces. 

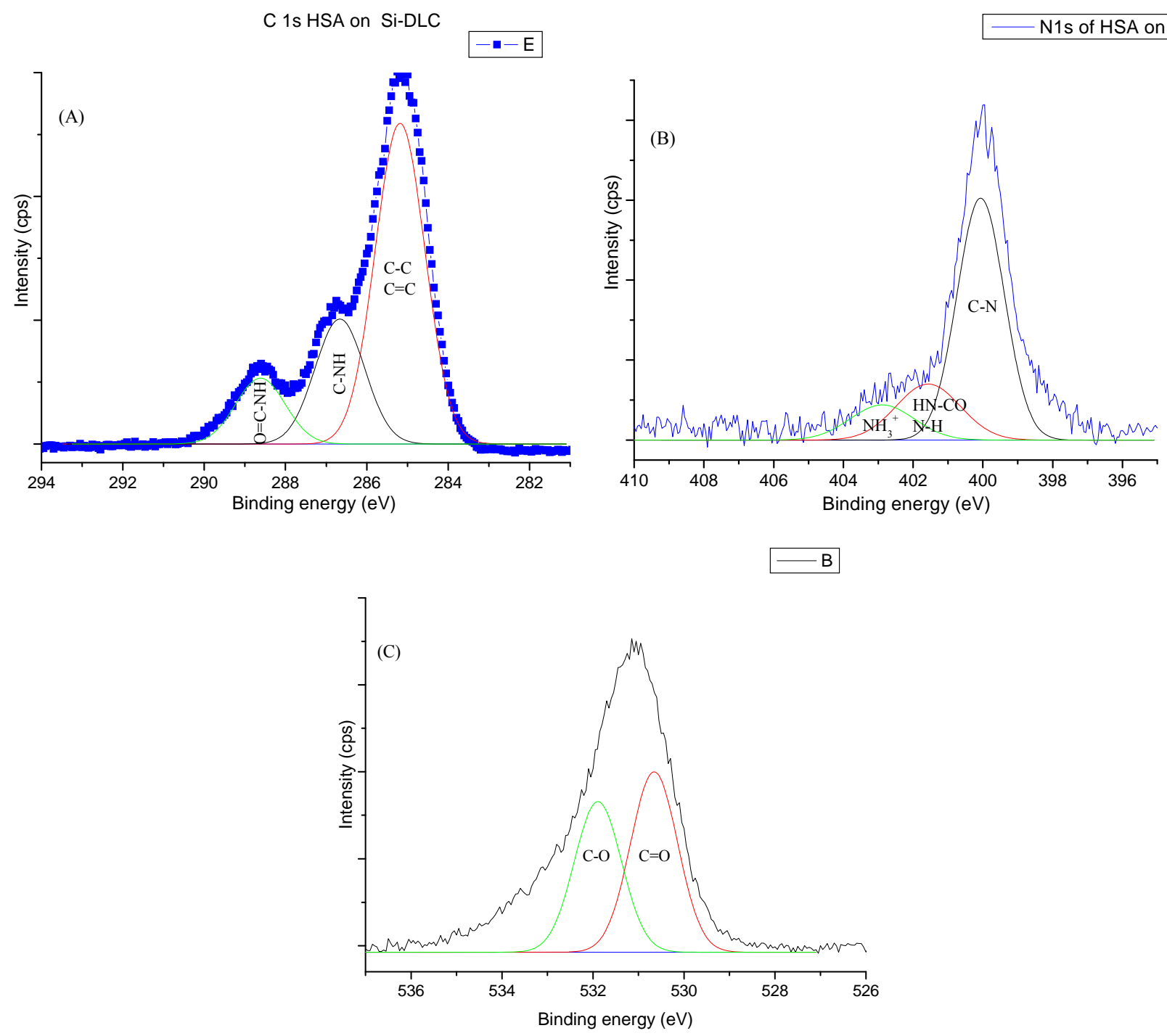

Figure 7. The XPS C1s (A), N1s (B) and O1s (C) spectra for adsorbed HSA onto DLC and Si-DLC.

structure [28]. The Amide I band of free HSA, is located at $1650 \mathrm{~cm}^{-1}$, whilst in case of adsorbed HSA onto doped DLC, the same band observed at around $1641 \mathrm{~cm}^{-1}$. A quantitative analysis of the amide I region can be estimated by curve fitting confirms the gradual evolution in the secondary structure content.

To investigate changes in the secondary structure of HSA after it is conjugated to the coated DLC surface, the deconvulation and second derivative of amide I band has been applied. Spectral deconvolution resolved four peaks for the amide I band for the free HSA, (Figure 9). A band located at $1612 \mathrm{~cm}^{-1}$ which is correlated to aromatic rings. The second component was seen at $1629 \mathrm{~cm}^{-1}$ and can be attributed to $\beta$-sheet structure [29]. Band at around $1663 \mathrm{~cm}^{-1}$ is related to $\alpha$-helix [30], and the last fitted peak detected at $1675 \mathrm{~cm}^{-1}$ which is return to antiparallel $\beta$-sheets components [31]. The quantitative ana- lysis of the amide I spectra of free HSA peptide indicates that there is more than $57 \%$ of $\alpha$-helix and $\sim 17 \%$ of $\beta$ sheet conformation (Table 3 ). The obtained results are in good agreement with the data reported by Bouhekka et al. [32].

Whilst the deconvulated of the same band after adsorption of HSA on to surface of samples, gives five secondary peaks at $\sim 1611 \mathrm{~cm}^{-1}$ (aromatic ring), $\sim 1630 \mathrm{~cm}^{-1}$ ( $\beta$-sheet), $1644 \mathrm{~cm}^{-1}$ (random coil), $1664 \mathrm{~cm}^{-1}$ ( $\alpha$-helix) and $\sim 1679 \mathrm{~cm}^{-1}(\beta$-sheet anti parallel). The $\beta$-sheet is slightly increased from $(17 \%$ to $\sim 25 \%)$. Furthermore, a decrease in $\alpha$-helical contribution is observed from $(57 \%$ to $45 \%$ ) (Figure 9). These could be attributable to the enhancing of HSA aggregation on to surfaces. The results are similar to those obtained by Khan et al. [33].

The amide II is arising from the in-plane N-H bending mode $(40-60) \%$ of the potential energy, and the rest of 


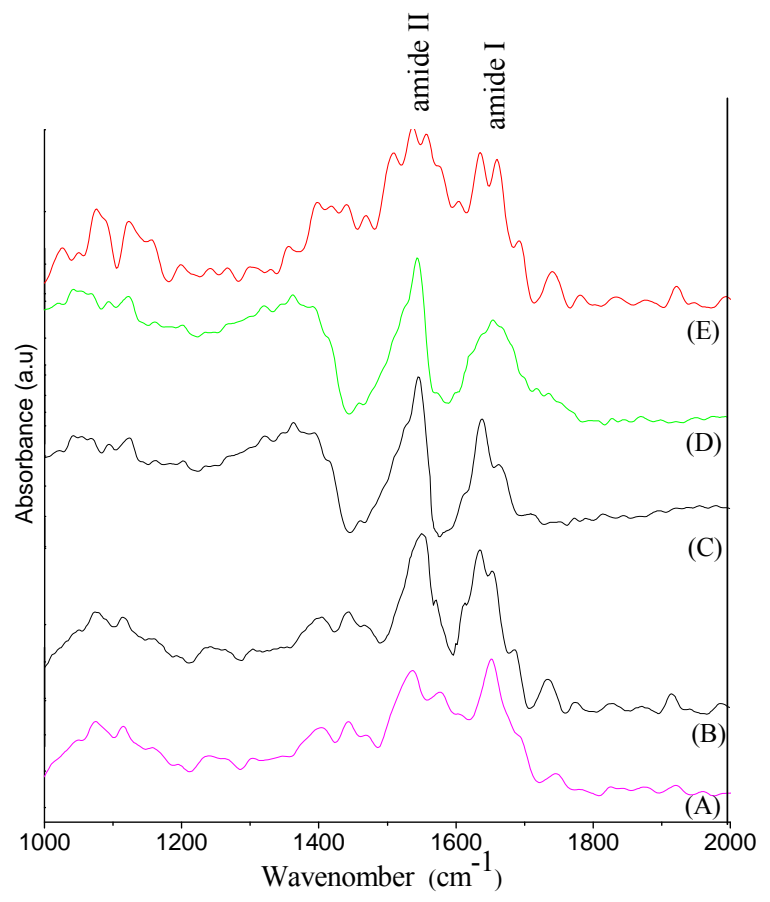

Figure 8. FTIR Spectra of HSA before (A) and after adsorbed on DLC (B), SI (C), SII (D) and SIII (E) surfaces.

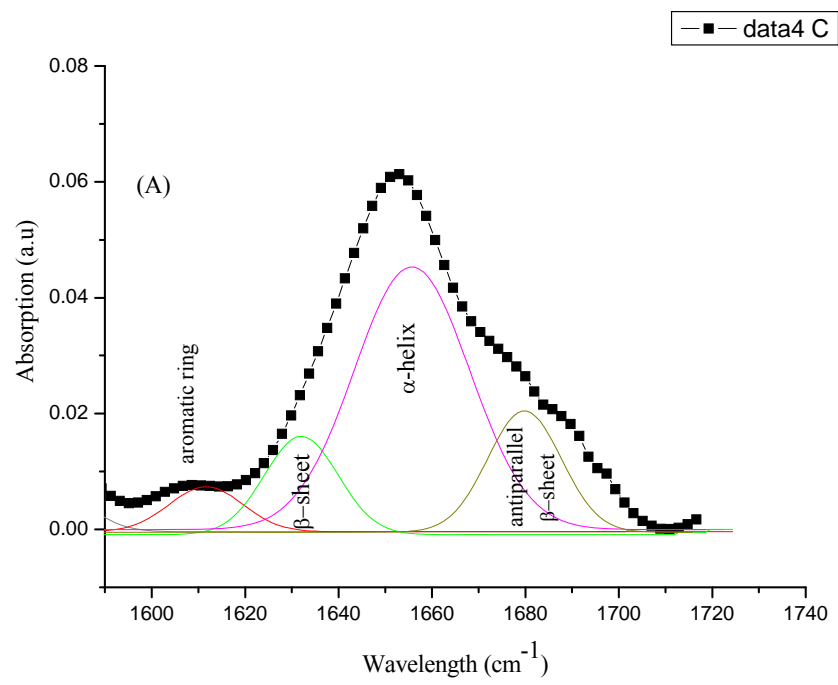

the potential energy emerges from the C-N $(20-40) \%$ and $\mathrm{C}-\mathrm{C}$ about $10 \%$ stretching vibrations [34]. In case of free HSA, the amide II shows a maximum of absorbance that shifts from $1559 \mathrm{~cm}^{-1}$ to lower wavenumbers (1553 $\mathrm{cm}^{-1}$ ) upon HSA adsorption onto DLC-coated surfaces. This shift can be correlated to the change of protein conformation during the adsorption [35]. In all these processes a hydrogen bond plays a dominant role in deciding the structure of the aggregate [36].

\section{Conclusions}

The results indicated that DLC films are established to consist of a mixture of tetrahedral $\left(\mathrm{sp}^{3}\right)$ and trigonal $\left(\mathrm{sp}^{2}\right)$ bonding. XPS data showed that the $\mathrm{sp}^{3} / \mathrm{sp}^{2}$ ratio increases with increasing silicon concentration in the DLC film. Furthermore, FTIR analysis showed that silicon incorporation DLC gives rise to the formation of $\mathrm{Si}-\mathrm{C}$ bond, which tends to increase in the fraction of $\mathrm{sp}^{3}$ bonded carbon in DLC film.

Followed by exposure to protein, a new band of nitrogen (N1s) appeared at the XPS spectra of the doped and undoped DLC surfaces. As well as a specific broad peak was observed at $\sim 288.4 \mathrm{eV}$ could be assigned to peptide

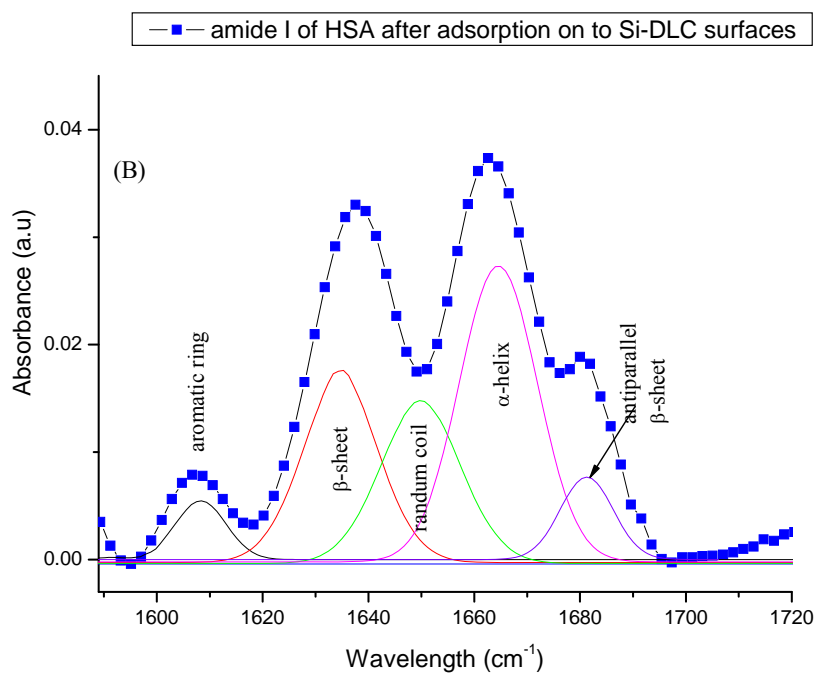

Figure 9. Curve-fitting analysis of the amide I in FTIR; for free HSA (A) and adsorbed on SIII (B).

Table 3. FTIR analysis of the amide I band of free and adsorbed HSA onto DLC and Si-DLC samples.

\begin{tabular}{|c|c|c|c|c|c|c|}
\hline \multirow{2}{*}{ Amide I bands } & \multicolumn{2}{|c|}{ Free HSA } & \multicolumn{2}{|c|}{ HSA adsorbed on DLC } & \multicolumn{2}{|c|}{ HSA adsorbed on SIII } \\
\hline & $\left(\mathrm{cm}^{-1}\right)$ & Band \% & $\left(\mathrm{cm}^{-1}\right)$ & Band \% & $\left(\mathrm{cm}^{-1}\right)$ & Band \% \\
\hline$\beta$-sheet & 1629 & 17.86 & 1631 & 25.82 & 1633 & 26.91 \\
\hline Random coil & & & 1644 & 7.1 & 1645 & 8.3 \\
\hline$\beta$-sheet anti parallel & 1675 & 10.54 & 1679 & 9.14 & 1681 & 8.66 \\
\hline
\end{tabular}


bond. In addition of, the presence of protonated amino groups $\left(\mathrm{NH}_{3}^{+}\right)$at $402.6 \mathrm{eV}$, this might suggesting that HSA bounded on the surfaces through the carboxyl group and the amino group has not interact strongly with the surface.

FTIR spectra revealed the presence of amide I and II at $1650 \mathrm{~cm}^{-1}$ and $1559 \mathrm{~cm}^{-1}$ belonging to protein. The results also suggested that relatively the adsorbed amount of HSA increased with increasing of silicon content on the DLC film. The presence studies have revealed that modifying the surface of DLC by incorporation of silicon can improve its biocompatibility of the implant; however, further studies are required to obtain a better understanding of protein adsorption in vivo.

\section{Acknowledgements}

The authors would like to thank all of the staff at Northern Ireland Bio-Engineering Centre (NIBEC), University of Ulster for their support, and also thanks to Sandra Adamson at LG, for her technical assistance.

\section{REFERENCES}

[1] C. M. Alves, R. L. Reis and J. A. Hunt, "The Competitive Adsorption of Human Proteins onto Natural-Based Biomaterials," Journal of the Royal Society Interface, Vol. 7, No. 50, 2010, pp. 1367-1377. doi:10.1098/rsif.2010.0022

[2] T. Hasebe, A. Hotta, H. Kodama, A. Kamijo, K. Takahashi and T. Suzuki, "Recent Advances in Diamond-Like Carbon Films in the Medical and Food Packing Fields," New Diamond and Fornier Carbon Technology, Vol. 17, No. 6, 2007, pp. 263-279.

[3] H. W. Choi, R. H. Dauskardt, S. C. Lee, K. R. Lee and K. H. Oh, "Characteristic of Silver Doped DLC Films on Surface Properties and Protein Adsorption," Diamond \& Related Materials, Vol. 17, No. 3, 2008, pp. 252-257. doi:10.1016/j.diamond.2007.12.034

[4] D. Grimanelis, S. Yang, O. Bohme, E. Roman, A. Alberdi, D. G. Teer and J. M. Albella, "Carbon Based Coating for High Temperature Cutting Tools," Applications, Diamond and Related Materials, Vol. 11, No. 2, 2002, pp. 176-184. doi:10.1016/S0925-9635(01)00566-0

[5] J. I. Onate, M. Comin, I. Braceras, A. Garcia, J. L. Viviente, M. Brizuela, N. Garagorri, J. L. Perisb and J. I. Alava, "Wear Reduction Effect on Ultra-High-MolecularWeight Polyethylene by Application of Hard Coatings and Ion Implantation on Cobalt Chromium Alloy, as Measured in a Knee Wear Simulation Machine," Surface Coatings Technology, Vol. 142-144, 2001, pp. 1056-1062. doi:10.1016/S0257-8972(01)01074-X

[6] A. Alanazi, C. Nojiri, T. Kido, T. Noguchi, Y. Ohgoe, T. Matsuda, K. Hirakuri, A. Funakubo, K. Sakai and Y. Fukui, "Engineering Analysis of Diamond-Like Carbon Coated Polymeric Materials for Biomedical Applications," Artificial Organs, Vol. 24, No. 8, 2000, pp. 624-627. doi:10.1046/j.1525-1594.2000.06576.x
[7] R. K. Roy, H. W. Choi, J. W. Yi, M. W. Moon, K. R. Lee, D. K. Han, J. H. Shin, A. Kamijo and T. Hasebe, "Hemocompatibility of Surface-Modified, Silicon-Incorporated, Diamond-Like Carbon Films," Acta Biomaterialia, Vol. 5, No. 1, 2009, Article ID: 249256. doi:10.1016/j.actbio.2008.07.031

[8] S. C. H. Kwok, W. Zhang, G. J. Wan, D. R. McKenzie, M. M. M. Bilek and P. K. Chu, "Hemocompatibility and Anti-Bacterial Properties of Silver Doped Diamond-Like Carbon Prepared by Pulsed Filtered Cathodic Vacuum Arc Deposition," Diamond \& Related Materials, Vol. 16, No. 4-7, 2007, pp. 1353-1360. doi:10.1016/j.diamond.2006.11.001

[9] M. H. Ahmed and J. A. Byrne, "Effect of Surface Structure and Wettability of DLC and N-DLC Thin Films on Adsorption of Glycine," Applied Surface Science, Vol. 258, No. 12, 2012, pp. 5166-5174. doi:10.1016/j.apsusc.2012.01.162

[10] M. H. Ahmed, J. A. Byrne and J. McLaughlin, "Evaluation of Glycine Adsorption on Diamond Like Carbon (DLC) and Fluorinated DLC Deposited by Plasma-Enhanced Chemical Vapour Deposition (PECVD)," Surface \& Coatings Technology, Vol. 209, 2012, pp. 8-14. doi:10.1016/j.surfcoat.2012.07.011

[11] M. Ahmed, A. J. Byrne, J. McLaughlin, A. Elhissi, D. A. Phoenix and W. Ahmed, "Vibrational and AFM Studies of Adsorption of Glycine on DLC and Silicon-Doped DLC," Journal of Materials Science, Vol. 47, No. 4, 2012, pp. 1729-1736. doi:10.1007/s10853-011-5952-3

[12] C. Liu, G. Q. Li, W. X. Chen, Z. X. Mu, C. W. Zhang and L. Wang, "The Study of Doped DLC Films by Ti Ion Implantation," Thin Solid Films, Vol. 475, No. 1-2, 2005, pp. 279-282. doi:10.1016/j.tsf.2004.08.051

[13] G. H. Hsiue, S. D. Lee, P. C. T. Chang and C. Y. Kao, "Surface Characterization and Biological Properties Study of Silicone Rubber Membrane Grafted with Phospholipid as Biomaterial via Plasma Induced Graft Copolymerization," Journal of Biomedical Materials Research, Vol. 42, No. 1, 1998, pp. 134-147. doi:10.1002/(SICI)1097-4636(199810)42:1<134::AID-JB M17>3.0.CO;2-L

[14] J. C. Damasceno, S. S. Camargo Jr., F. L. Freire Jr. and R. Carius, "Deposition of Si-DLC Films with High Hardness, Low Stress and High Deposition Rates," Surface and Coatings Technology, Vol. 133-134, 2000, pp. 247-252. doi:10.1016/S0257-8972(00)00932-4

[15] N. Moolsradoo, S. Abe and S. Watanabe, "Thermal Stbility and Tribological Performance of DLC-SiO Films," Advances in Materials Science and Engineering, Vol. 2011, 2011, Article ID: 483437.

[16] S. Kelly, E. M. Regan, J. B. Uney, A. D. Dick, J. P. McGeehan, E. J. Mayer and F. Claeyssens, "Patterned Growth of Neuronal Cells on Modified Diamond-Like Carbon Substrates," Biomaterials, Vol. 29, No. 24-25, 2008, pp. 2573-2580. doi:10.1016/j.biomaterials.2008.03.001

[17] M. Ahmed, J. Anthony Byrne and J. A. D. McLaughlin, "Glycine Adsorption onto DLC and N-DLC Thin Films 
Studied by XPS and AFM," e-Journal of Surface Science and Nanotechnology, Vol. 7, 2009, pp. 217-224. doi:10.1380/ejssnt.2009.217

[18] A. Bendavid, P. J. Martin, C. Comte, E. W. Preston, A. J. Haq, F. S. M. Ismail and R. K. Singh, "The Mechanical And Biocompatibility Properties of DLC-Si Films Prepared by Pulsed DC Plasma Activated Chemical Vapor Deposition," Diamond \& Related Materials, Vol. 16, No. 8, 2007, pp. 1616-1622. doi:10.1016/j.diamond.2007.02.006

[19] Q. Zhao, Y. Liu, C. Wang and S. Wang, "Bacterial Adhesion on Silicon-Doped Diamond-Like Carbon Films," Diamond and Related Materials, Vol. 16, No. 8, 2007, pp. 1682-1687. doi:10.1016/j.diamond.2007.03.002

[20] R. K. Roy, S. J. Park, H. W. Choil, K. R. Lee, J. H. Kim, D. K. Han, J. H. Shin, H. G. Kim, S. H. Ahn, J. G. Kim, S. J. Park and K. R. Lee, "Hemocompatibility of Surface Modified Si Incorporated Diamond-Like Carbon Films," Thin Solid Films, Vol. 482, 2005, pp. 299-304.

[21] R. Paul, S. N. Das, S. Dalui, R. N. Gayen, R. K. Roy, R. Bhar and A. K. Pal, "Synthesis of DLC Films with Different $\mathrm{sp}^{2} / \mathrm{sp}^{3}$ Ratios and Their Hydrophobic Behaviour," Journal of Physics D: Applied Physics, Vol. 41, No. 5, 2008, Article ID: 055309. doi:10.1088/0022-3727/41/5/055309

[22] W. J. Hsieh, P. S. Shih, C. C. Lin, C. Y. Wang and H. C. Shi, "Structure and Optical Property of the a-C:N Films Synthesized by Filtered Cathode Vacuum Arc," Surface and Coatings Technology, Vol. 200, No. 10, 2006, pp. 3175-3178. doi:10.1016/j.surfcoat.2005.07.038

[23] M. N. Huda, Y. Yan and M. M. Al-Jassim, "On the Existence of Si-C Double Bonded Graphene-Like Layers," Chemical Physics Letters, Vol. 479, No. 4-6, 2009, pp. 255-258. doi:10.1016/j.cplett.2009.08.028

[24] N. Fainer, Y. Rumyantsev, M. Kosinova, E. Maximovski, V. Kesler, V. Kirienko and F. Kuznetsov, "Low-k Dielectrics on Base of Silicon Carbon Nitride Films," Surface and Coatings Technology, Vol. 201, No. 22, 2007, pp. 9269-9274. doi:10.1016/j.surfcoat.2007.04.046

[25] H. Yoneyama and T. Torimoto, "Titanium Dioxide/Adsorbent Hybrid Photocatalysts for Photodestruction of Organic Substances of Dilute Concentrations," Catalysis Today, Vol. 58, No. 2-3, 2000, pp. 133-140.

[26] T. Kesvatera, B. Jonsson, A. Telling, V. Tougu, H. V. E. Thulin and S. Linse, "A Protein Optimized for Calcium Binding at Neutral pH," Biochemistry, Vol. 40, No. 50, 2001, pp. 15334-15340.

[27] H. J. Kim, I.-S. Bae, S.-J. Cho, J.-H. Boo, B.-C. Lee, J. Heo, I. Chung and B. Hong, "Synthesis and Characteristics of $\mathrm{NH}_{2}$-Functionalized Polymer Films to Align and
Immobilize DNA Molecules N-Containing Moieties Could Be Useful," Nanoscale Research Letters, Vol. 7, 2012, pp. 30-37. doi:10.1186/1556-276X-7-30

[28] M. Bouchard, J. Zurdo, E. J. Nettleton, C. M. Dobson, and C. V. Robinson, "Formation of Insulin Amyloid Fibrils Followed by FTIR Simultaneously with CD and Electron Microscopy," Protein Science, Vol. 9, No. 10, 2000, pp. 1960-1967. doi:10.1110/ps.9.10.1960

[29] M. Jackson and H. H. Mantsch, "The Use and Misuse of FTIR Spectroscopy in the Determination of Protein Structure," Critical Reviews in Biochemistry and Molecular Biology, Vol. 30, No. 2, 1995, pp. 95-120. doi: $10.3109 / 10409239509085140$

[30] K. L. Munro, K. R. Bambery, E. A. Carter, L. Puskar, M. J. Tobin, B. R. Wood and C. T. Dillon, "Synchrotron Radiation Infrared Microspectroscopy of Arsenic-Induced Changes to Intracellular Biomolecules in Live Leukaemia Cells," Vibrational Spectroscopy, Vol. 53, No. 1, 2010, pp. 39-44. doi:10.1016/j.vibspec.2010.02.004

[31] C. Chadefaux, A.-S. L. Ho, L. Bellot-Gurlet and I. Reiche, "Curve-Fitting Micro-ATR-FTIR Studies of the Amide I and II Bands of Type I Collagen Archaeological Bone Materials," e-Preservation Science, Vol. 6, 2009, pp. 129-137.

[32] A. Bouhekka and T. Burgi, "In Situ ATR-IR Spectroscopy Study of Adsorbed Protein: Visible Light Denaturation of Bovine Serum Albumin on $\mathrm{TiO}_{2}$," Applied Surface Science, Vol. 261, 2012, pp. 369-374.

doi:10.1016/j.apsusc.2012.08.017

[33] M. W. Khan, Z. Rasheed, W. A. Khan and R. Ali, "Biochemical, Biophysical, and Thermodynamic Analysis of in Vitro Glycated Human Serum Albumin," Biochemistry (Moscow), Vol. 72, No. 2, 2007, pp. 146-152. doi:10.1134/S0006297907020034

[34] M. L. Gulrajani, K. P. Brahma, P. S. Kumar and R. Purwar, "Application of Silk Sericin to Polyester Fabric," Journal of Applied Polymer Science, Vol. 109, No. 1, 2008, pp. 314-321. doi:10.1002/app.28061

[35] M. Dumitrascu, V. Meltzer, E. Sima, M. Virgolici, M. G. Albu, A. Ficai, V. Moise, R. Minea, C. Vancea, A. Scarisoreanu and F. Scarlat, "Characterization of Electron Beam Irradiated Collagen-Polyprolidone (PVP) and CollagenDexran (DEX) Blends," Digest Journal of Nanomaterials and Biostructures, Vol. 6, 2011, pp. 1793-1803.

[36] P. Juszczyk, A. S. Kołodziejczyk and Z. Grzonka, "FTIR Spectroscopic Studies on Aggregation Process of the $\beta$ Amyloid 11-28 Fragment and Its Variants," Journal of Peptide Science, Vol. 15, No. 1, 2009, pp. 23-29. doi:10.1002/psc.1085 